\title{
Bimetallic Zeolitic Imidazolate Framework-derived Porous Carbon as Efficient Bifunctional Electrocatalysts for Zn-air Battery
}

\author{
Zihan Meng ${ }^{1,2}$, Haopeng Cai ${ }^{1, *}$, Haolin Tang ${ }^{2, *}$ \\ ${ }^{1}$ School of Material Science and Engineering, Wuhan University of Technology, Wuhan, China, \\ 430070 \\ ${ }^{2}$ State Key Laboratory of Advanced Technology for Materials Synthesis and Processing, Wuhan \\ University of Technology, Wuhan, China, 430070 \\ *E-mail: cai_haopeng@whut.edu.cn, thln@whut.edu.cn
}

doi: $10.20964 / 2018.06 .20$

Received: 27 January 2018 / Accepted: 21 March 2018 / Published: 10 May 2018

The development of low-cost and efficient oxygen reduction reaction (ORR) and oxygen evolution reaction (OER) electrocatalyst is critical for widespread application of fuel cells and metal-air batteries. Herein, hierarchically structured porous carbon bifunctional electrocatalyst is synthesized by using soft template and metal organic framework (MOF) precursor. The as-obtained electrocatalyst exhibits superior catalytic activity due to its hierarchical porous architecture as well as high surface area $\left(1539 \mathrm{~m}^{2} \mathrm{~g}^{-1}\right)$. For ORR, the prepared catalyst shows more positive activity, superior long-term stability and remarkable methanol tolerance compared with commercial $\mathrm{Pt} / \mathrm{C}$ catalyst in alkaline condition. In addition, the reported catalyst also has a higher OER activity than commercial $\mathrm{Pt} / \mathrm{C}$ catalyst in alkaline media. We further demonstrate that the catalyst also presents outstanding $\mathrm{Zn}$-air battery performance.

Keywords: Metal organic framework, soft template, oxygen reduction reaction, oxygen evolution reaction; Zn-air battery

\section{$\underline{\text { FULL TEXT }}$}

(C) 2018 The Authors. Published by ESG (www.electrochemsci.org). This article is an open access article distributed under the terms and conditions of the Creative Commons Attribution license (http://creativecommons.org/licenses/by/4.0/). 